\title{
A three-phase epidemiological study of short and long sleepers in a middle-aged Chinese population: prevalence and characteristics
}

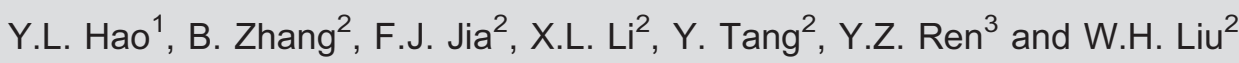 \\ ${ }^{1}$ Department of Human Anatomy, Guangzhou Medical University, Guangzhou, China \\ ${ }^{2}$ Guangdong General Hospital, Guangdong Academy of Medical Sciences, Guangdong Mental Health Centre, Guangzhou, China \\ ${ }^{3}$ Zhongshan The Third People's Hospital, Zhongshan, China
}

\begin{abstract}
Epidemiological studies of short and long sleepers have not been conducted previously. We collected socioeconomic, psychological, and polysomnographic characteristics of 6501 parents (3252 men and 3249 women) of 4036 primary school children in Guangzhou city. The study data were collected in three phases. The overall prevalence of short ( $5 \mathrm{~h}$ or less) and long $(10 \mathrm{~h}$ or more) sleep duration was 0.52 and $0.64 \%$, respectively. Long sleepers had higher Eysenck Personality Questionnaire neuroticism scores [odds ratio $(\mathrm{OR})=1.224,95 \%$ confidence interval $(\mathrm{Cl})=1.047-1.409$ ] and lower education levels $(\mathrm{OR}=0.740,95 \% \mathrm{Cl}=0.631-0.849)$ than short sleepers. In the polysomnographic assessment, short, long, and normal sleepers $(7-8 \mathrm{~h}$ ) shared similar durations of Stage 3 sleep (short $=25.7 \pm 10.7$, long $=20.3 \pm 7.9$, and normal $=28.0 \pm 12.8 \mathrm{~min}$, $F=1.402, P=0.181)$. In daytime multiple sleep latency tests, short sleepers $(10 / 19,52.6 \%)$ were more prone to have a short sleep latency $(\leq 8 \mathrm{~min})$ than long sleepers $(2 / 23,8.7 \%)$. In addition to different sleep durations, neuroticism might also contribute to differences between short and long sleepers in social achievements. Stage 3 sleep might be essential for humans. The short sleep latency ( $\leq 8 \mathrm{~min}$ ) of short sleepers in multiple sleep latency tests should be interpreted cautiously, since it was of the same severity as required for a diagnosis of narcolepsy or idiopathic hypersomnia.
\end{abstract}

Key words: Short sleeper; Long sleeper; Prevalence; Characteristics; Chinese

\section{Introduction}

Short and/or long sleep duration is usually related to pathological conditions such as obesity, hypertension, and diabetes $(1,2)$. However, at the two extremes of the normal sleep duration continuum, genuine short sleepers (SS) and long sleepers (LS) must exist (3). According to the International Classification of Sleep Disorders, second edition (ICSD-2), an SS is a person with a routine pattern of $5 \mathrm{~h}$ or less, and an LS is a person who consistently sleeps $10 \mathrm{~h}$ or more in $24 \mathrm{~h}$, or substantially more than that conventionally obtained by others in his or her age group. These extremes of sleep duration cannot be explained by the presence of another sleep disorder, medical or neurological disorders, mental disorders, medicine use, or substance-use disorders (3).

To date, the SS/LS phenomenon is an interesting but under-researched area. Most previous studies were conducted in the last century and focused on psychological and polysomnographic (PSG) characteristics of SS and LS. Hartmann et al. $(4,5)$ described the psychological characteristics of SS as ambitious, energetic "nonworriers" and LS as reflective and critical "worriers". Webb and Friel (6) reported that SS and LS scores on a battery of personality, scholastic, and medical measures did not differ significantly. Hicks and Pellegrini (7) and Hicks et al. (8) reported that SS had significantly higher scores in a particular anxiety. It would tend to support Hartmann's hypothesis if a particular anxiety were interpreted as a measure of drive level. In addition, Hicks et al. (9) hypothesized that SS had greater levels of emotion-focused coping, and LS had greater levels of problem-focused coping. For the PSG characteristics, Webb and Agnew Jr. (10) and Hartmann et al. (4),

Correspondence: B. Zhang, Guang Dong General Hospital, Guang Dong Academy of Medical Science, Guang Dong Mental Health Centre, No. 123, Hui Fu Xi Road, Guangzhou, 510120, China. Fax: +86-20-8186-2664. E-mail: zhang73bin@hotmail.com 
respectively, found that SS and LS spent similar and perfectly normal amounts of time in Stage 3 sleep, and LS spent far more time in rapid eye movement (REM) sleep and Stage 2 sleep, and had higher REM densities than SS. Aeschbach et al. (11-13) hypothesized that SS and LS had identical homeostatic sleep-regulatory mechanisms, but SS lived under and tolerated higher homeostatic sleep pressures than LS. All in all, these previous limited and conflicting studies confound the psychosocial and PSG characteristics of SS and LS. Some limitations can also be noted in that they included different criteria for SS and LS and most study samples comprised young college students.

It was noted that there is little epidemiological information about SS and LS because no well-designed studies have been conducted. In a study of more than one million subjects, $4.0 \%$ (3.6\% men and $4.3 \%$ women) reported sleeping $5 \mathrm{~h}$ or less per night, and $1.7 \%(2 \%$ men and $1.5 \%$ women) reported sleeping at least $10 \mathrm{~h}$ per night (14). However, not all of them were qualified as SS or LS according to ICSD-2.

In this three-phase epidemiological study, we explored socioeconomic, psychosocial, and PSG characteristics of SS and LS in a middle-aged Chinese population. Additional emphasis was placed on calculating the prevalence of SS and LS in the general population. To the best of our knowledge, this is the first epidemiological study of SS and LS.

\section{Material and Methods}

\section{Overview of the project}

The Independent Ethics Committee of Guangdong Provincial Mental Health Center approved the current study. The target population was recruited from parents of 4036 primary school-aged children from five randomly selected schools in Guangzhou city. None of the 4036 children were related. Details of the study procedures are described below.

\section{Participants and procedures}

In this study, SS was defined as a subject who sleeps $5 \mathrm{~h}$ or less per $24 \mathrm{~h}$, and LS was defined as a subject who sleeps $10 \mathrm{~h}$ or more per $24 \mathrm{~h}$ (3). Furthermore, subjects who slept $7-8 \mathrm{~h}$ per $24 \mathrm{~h}$ were recruited as a control group (normal sleeper, NS). All three groups were evaluated in three phases (Phase 1, questionnaire; Phase 2, clinical interview; and Phase 3, PSG). Men and women aged 30 to 60 years were eligible to participate. They were excluded if they were currently shift workers, if they currently had significant sleep disorders (e.g., obstructive sleep apnea, restless legs syndrome, or periodic limb movement disorder), or if they had a serious psychiatric and medical condition in the previous year. The procedures included in the three phases of the study are shown in the flow chart in Figure 1.

\section{Phase 1 study}

A total of 4036 envelopes containing a child sleep questionnaire, two brief sleep questionnaires for parents (one for the father and one for the mother), an invitation letter, and an informed consent form were distributed to children in Grades 1 to 6 from five randomly selected primary schools from September to December 2009. The parents' sleep questionnaire was modified from one used in our previous epidemiological study (15) and was specifically developed for use in the present study. It has been demonstrated to have satisfactory validity and internal consistency (Cronbach's $\alpha$ coefficient $=0.846$ ) (16). Teachers distributed the questionnaires to the children for completion by their parents. Parents rated the items in the questionnaires according to their children's and their own sleep patterns and sleep problems. The children's data will be reported in other articles. If the children did not return the questionnaire within 1 week, a reminder was issued by the class teacher. Written informed consent was collected with the returned questionnaires. A total of 6722 parents (3363 men and 3359 women) returned their questionnaires. The following questionnaires were excluded: those containing grossly incomplete or missing data on sleep patterns $(n=103)$ and those with less than $70 \%$ of the questions completed $(n=149)$. Thirty-one questionnaires were excluded for both reasons, thus a total of 221 questionnaires were excluded. The remaining questionnaires $\{\mathrm{n}=6501 ; 3252$ men and 3249 women; response rate $\approx 80.5 \%[6501 /(4036 \times 2)]\}$ represented the eligible study population.

The brief sleep questionnaire for parents consisted of 25 items on demographic characteristics; sleep patterns, specific syndromes of common sleep problems (e.g., insomnia, obstructive sleep apnea, restless legs syndrome, etc.), health status $(1=$ good, $2=$ poor $)$, and consumption of tea, coffee, cigarettes, and alcohol in the past year. To determine the sleep patterns, two questions were asked regarding weekdays and weekends: "What time do you usually go to bed?" and "What time do you usually get up?" Daily time in bed (TIB; number of hours) was calculated as the difference between wake-up time and bedtime, and mean TIB was calculated by the equation [(weekday $\mathrm{TIB} \times 5)+($ weekend TIB $\times 2) / 7]$. We assumed the usual sleep latency to be $15 \min (0.25 \mathrm{~h})$, so mean sleep duration (in $\mathrm{h}$ ) was calculated using the equation $\{[($ weekday $\mathrm{TIB} \times 5)+$ (weekend TIB $\times 2) / 7]-0.25\}$. Among the 6501 subjects (3252 men and 3249 women), there were 123 SS [1.9\% (123/6501), 2.1\% (67/3252) men, and 1.7\% (56/3249) women)], 136 LS [2.1\% (136/6501), 1.8\% (57/3252) men, and $2.4 \%$ (79/3249) women], and 1233 NS. No gender predominance of SS and LS was shown in the total population. The sleep disorders were evaluated by the following frequencies: $0=$ none, $1=$ less than once per month, $2=1-2$ times per month, $3=1-2$ times per week, 


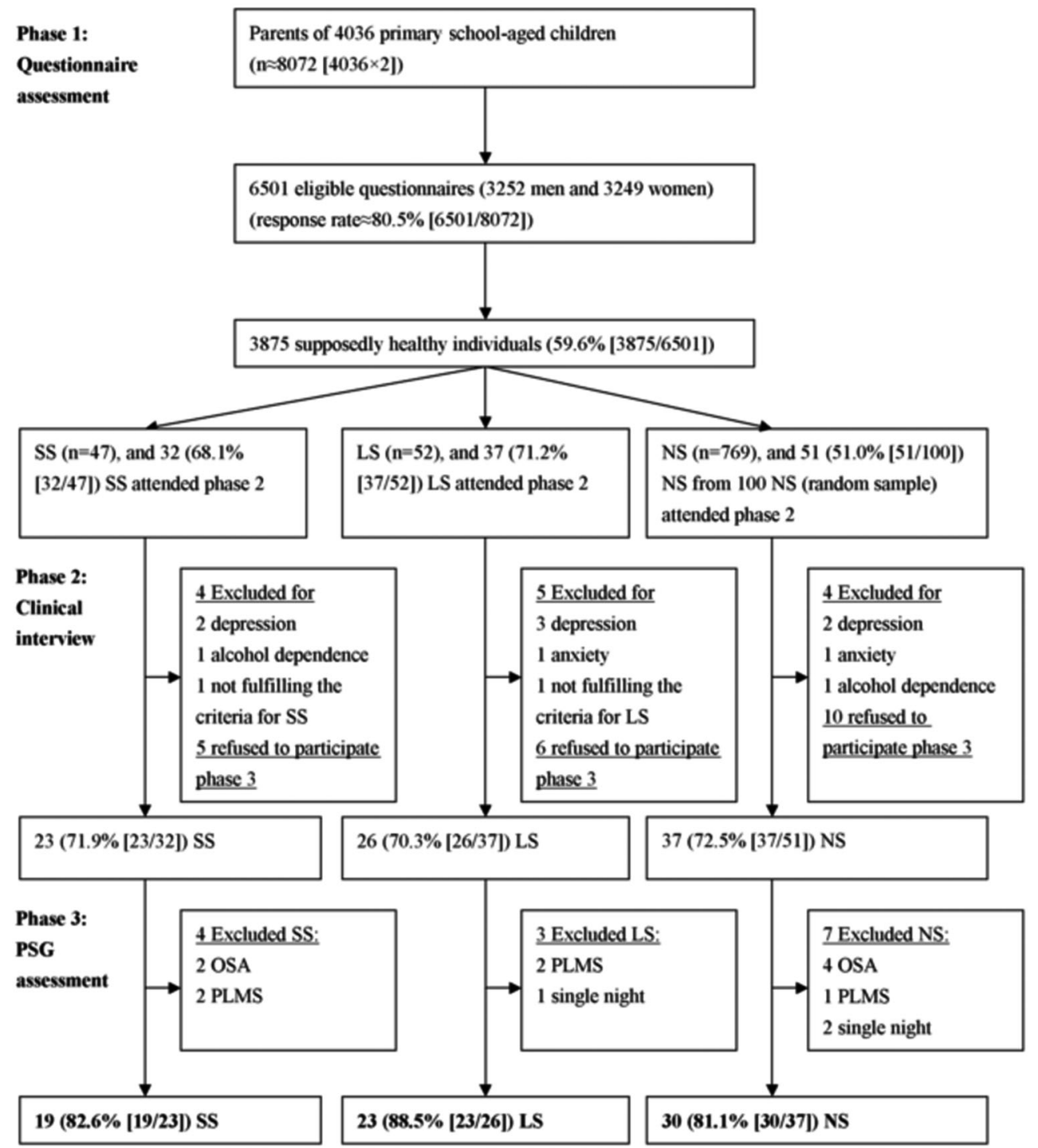

Figure 1. Flowchart documenting recruitment of short (SS), long (LS), and normal sleepers (NS). The target population was recruited from parents of 4036 primary school-aged children from 5 randomly selected primary schools in Guangzhou city. The remaining 6501 questionnaires from the respondents (3252 men and 3249 women, response rate $\approx 80.5 \%[6501 /(4036 \times 2)]$ represented the eligible study population. After three phases of evaluation (Phase 1: questionnaire assessment, Phase 2: clinical interview, Phase 3: sleep lab test), there were 19 SS, 23 LS, and 30 NS.

and $4=3$ or more times per week. If an individual reported any sleep disorder with a score of 4 or a poor health status in the past year, he/she was assumed to be unhealthy. Finally, 3875 subjects [59.6\% (3875/6501) total, 59.0\% (1919/3252) men, and 60.2\% (1956/3249) women] comprised the healthy population, without gender predominance $\left(\chi^{2}=0.961, P=0.327\right)$. Among these 3875 healthy subjects, there were 47 SS [1.2\% (47/3875) total, $1.3 \%(25 / 1919)$ men, and $1.1 \%(22 / 1956)$ women], 52 LS [1.3\% (52/3875) total, $1.2 \%(23 / 1919)$ men, and $1.5 \%$ (29/1956) women]. There were 769 NS control partici- pants. No gender predominance was observed among the SS and LS in the healthy subjects. In addition, the prevalence of SS $\left(\chi^{2}=8.077, \mathrm{P}=0.004\right)$ and LS $\left(\chi^{2}=7.677, \mathrm{P}=0.006\right)$ in the 3875 healthy subjects was significantly lower than that in the total population of 6501 subjects. Table 1 shows the prevalence of SS and LS in the total study population and in the healthy subjects.

\section{Phase 2}

We invited all 47 SS ( 25 men and 22 women), 52 LS (23 men and 29 women), and 100 randomly selected NS 
Table 1. Prevalence of short (SS) and long sleepers (LS) in the total sample $(n=6501)$ and in the sample of healthy subjects $(n=3875)$ and the adjusted prevalence of SS and LS.

\begin{tabular}{|c|c|c|c|c|c|c|c|c|c|c|}
\hline & \multicolumn{5}{|c|}{ SS } & \multicolumn{5}{|c|}{ LS } \\
\hline & $\begin{array}{l}\text { Total } \\
\text { n (\%) }\end{array}$ & $\begin{array}{l}\text { Men } \\
\mathrm{n}(\%)\end{array}$ & $\begin{array}{c}\text { Women } \\
\text { n (\%) }\end{array}$ & $\chi^{2}$ & $\mathrm{P}$ & $\begin{array}{l}\text { Total } \\
\text { n (\%) }\end{array}$ & $\begin{array}{c}\text { Men } \\
\text { n (\%) }\end{array}$ & $\begin{array}{c}\text { Women } \\
\mathrm{n}(\%)\end{array}$ & $\chi^{2}$ & $\mathrm{P}$ \\
\hline $\begin{array}{l}6501 \text { subjects } \\
\text { ( } 3252 \text { men and } \\
3249 \text { women) }\end{array}$ & $\begin{array}{c}123 \\
(1.9 \%)\end{array}$ & $\begin{array}{c}67 \\
(2.1 \%)\end{array}$ & $\begin{array}{c}56 \\
(1.7 \%)\end{array}$ & 0.992 & 0.319 & $\begin{array}{c}136 \\
(2.1 \%)\end{array}$ & $\begin{array}{c}57 \\
(1.8 \%)\end{array}$ & $\begin{array}{c}79 \\
(2.4 \%)\end{array}$ & 3.656 & 0.056 \\
\hline $\begin{array}{l}3875 \text { healthy subjects } \\
\text { (1919 men and } \\
1956 \text { women) }\end{array}$ & $\begin{array}{c}47 \\
(1.2 \%)\end{array}$ & $\begin{array}{c}25 \\
(1.3 \%)\end{array}$ & $\begin{array}{c}22 \\
(1.1 \%)\end{array}$ & 0.256 & 0.613 & $\begin{array}{c}52 \\
(1.3 \%)\end{array}$ & $\begin{array}{c}23 \\
(1.2 \%)\end{array}$ & $\begin{array}{c}29 \\
(1.5 \%)\end{array}$ & 0.908 & 0.318 \\
\hline Adjusted prevalence & $0.52 \%$ & $0.55 \%$ & $0.50 \%$ & 0.116 & 0.247 & $0.64 \%$ & $0.55 \%$ & $0.67 \%$ & 0.406 & 0.524 \\
\hline
\end{tabular}

[13.0\% (100/769) total, 50 men, and 50 women] among the healthy subjects by phone. Of these, 32 SS (12 men and 20 women), 37 LS (15 men and 22 women), and 51 NS (20 men and 31 women) attended the Phase 2 assessment, which involved a comprehensive clinical interview and completion of a packet of questionnaires. The Semistructured Clinical Interview (SCID-II) for Diagnostic and Statistical Manual (DSM)-IV axis I psychiatric disorders was used to conduct a diagnostic assessment by a qualified psychiatrist (17), and detailed sleep, physical, and psychiatric histories were obtained. A battery of questionnaires, including the Epworth Sleepiness Sale (ESS) (18), the Eysenck Personality Questionnaire (EPQ) (19), the Beck Depression Inventory (20), a Self-Report Questionnaire (SRQ) (21), a State/ Trait Anxiety Inventory (22), a Morningness/Eveningness Questionnaire (23), and a Type A Questionnaire (24) were completed by these recruited subjects.

In Phase 2, 13 subjects [4 SS (2 men and 2 women), 5 LS ( 2 men and 3 women), and 4 NS (2 men and 2 women)] were excluded because of psychiatric problems; 7 for depression (2 SS, 3 LS, and 2 NS), 2 for anxiety (1 LS and $1 \mathrm{NS}$ ), 2 for alcohol dependence (1 SS and 1 NS), and 2 who did not fulfill the criteria of sleep duration (1 SS and $1 \mathrm{LS}$ ). Twenty-one subjects [5 SS ( 3 men and 2 women), 6 LS ( 3 men and 3 women), and 10 NS (5 men and 5 women)] refused to attend the sleep laboratory study in Phase 3.

\section{Phase 3}

Eighty-six subjects [23 SS ( 7 men and 16 women), 26 LS (10 men and 16 women), and 37 NS (14 men and 23 women)] attended a sleep laboratory study in Phase 3. They all completed a 2-week sleep log prior to the sleep laboratory study. They were assessed by two consecutive nocturnal PSG to be followed by a daytime multiple sleep latency test (MSLT). All 86 subjects were asked to keep their usual bedtimes and wake times on both nights. Because of the first-night effect, the first night was regarded as an adaptation night. PSG variables on the second night and the MSLT were analyzed in this research. Polysomnograms were performed using an Embla sleep monitoring system (Embla N7000, Remlogic, USA).

The basic PSG recordings included a standard electroencephalogram (F4-A1, C4-A1, O2-A1, C3-A2), an electrooculogram (LE-A2, RE-A1), a chin electromyogram (EMG), a bilateral leg EMG (anterior tibialis muscle), an electrocardiogram, nasal airflow pressure, snore microphone, thoracic and abdominal respiratory efforts, oxyhemoglobin saturation, and body position. All of the sleep variables were derived from the visual scoring of recordings using standard criteria and were divided into two groups: sleep continuity indices and sleep architecture indices. Sleep continuity indices included the total recording time (TRT; lights out to lights on in minutes), total sleep time (TST), sleep efficiency (TST divided by TRT), sleep latency (lights out to the first epoch of any sleep in minutes), REM latency (sleep onset to the first epoch in REM stage in minutes), wake after sleep onset (WASO; Stage W during TRT minus sleep latency, in minutes), and arousal index (the number of arousals divided by TST). Sleep architecture indices included the duration (number of hours) and percentages in each stage (the time in Stage 1, Stage 2, Stage 3, and Stage REM divided by the TST) (25). A five-nap MSLT was performed according to standard recommendations to determine sleep latency and sleep onset REM (SOREM) (26).

Because sleep duration might be disturbed by obstructive sleep apnea and periodic limb movement disorder, subjects with a periodic limb movement index $>15 / \mathrm{h}$ or an apnea-hypopnea index $>15 / \mathrm{h}$ were excluded. In Phase 3, 14 subjects [4 SS (1 man and 3 women), 3 LS (1 man and 2 women), and 7 NS (3 men and 4 women)] were excluded from the final analysis, including 6 subjects with an apnea-hypopnea index $>15 / \mathrm{h}$ (2 SS and $4 \mathrm{NS}$ ), 5 subjects with a periodic limb movement index $>15 / \mathrm{h}$ ( $2 \mathrm{SS}, 2 \mathrm{LS}$, and $1 \mathrm{NS}$ ), and 3 subjects with one-night PSG (1 LS and 2 NS). Finally, 19 SS ( 6 men and 13 women), 23 LS (9 men and 14 women), and 30 NS (11 men and 19 women) comprised valid samples in the current study. 


\section{Statistical analysis}

Data are reported as means $\pm S D$ for continuous variables and as numbers or percentages for categorical variables. Parametric and nonparametric data were compared using an independent $t$-test and the MannWhitney U-test, respectively (two groups). One-way analysis of variance (ANOVA) and the Kruskal-Wallis test were performed for comparing parametric and nonparametric data ( $\geqslant 3$ groups). Significant effects in ANOVA were further examined with post hoc tests using the least significant difference method with a Bonferroni correction for multiple comparisons. The Mann-Whitney U-test with adjusted $P$ values (significant at $P=0.017$ ) was used for multiple pairwise comparisons. A chi-squared $\left(\chi^{2}\right)$ test was used to analyze the differences in categorical variables, and multiple $\chi^{2}$ tests with adjusted $P$ values (significant at $\mathrm{P}=0.017$ ) were used for multiple pairwise comparisons. Those variables with $\mathrm{P}<0.10$ were recruited to test potential related factors between SS and LS by logistic regression (except for basic demographic variables of age and gender). A two-sided 5\% level of significance was considered to be significant for other statistical tests. All statistical procedures were performed using the Statistical Package for the Social Sciences 17.0 for Windows (SPSS, Inc., USA).

\section{Results}

\section{Epidemiology}

We calculated the adjusted prevalence of SS and LS from the data obtained in the three study phases. A total of 19 SS were identified who satisfied the criteria of the three-phase evaluation in the current study. Fifteen of the 47 SS identified in Phase 1 refused to go to Phase 2. The proportion of healthy SS was 28/32 after the Phase 2 evaluation, so an estimated 13 of the 15 SS who were not evaluated $[15 \times(28 / 32)]$ could have passed Phase 2 . Five healthy SS in Phase 2 refused to be evaluated in Phase 3, so an estimated total of $18 \mathrm{SS}\{[15 \times(28 / 32)]+5\}$ missed attending Phase 3 . The proportion of healthy SS was 19/ 23 after the Phase 3 evaluation, so an estimated 15 of the SS who were not evaluated in Phase 2 and Phase 3 $\{[15 \times(28 / 32)]+5\} \times(19 / 23)\}$ could have passed Phase 3 . Thus, the adjusted prevalence of SS was $0.52 \%$ using the equation $\{19+[15 \times(28 / 32)+5] \times(19 / 23)\} /$ $6501 \times 100 \%$. Similarly, the adjusted prevalence of male SS was $0.55 \%$ using the equation $\{6+[13 \times(10 / 12)$ $+3] \times(6 / 7)\} / 3252 \times 100 \%$, and the adjusted prevalence of female SS was $0.50 \%$ using the equation $\{13+[2 \times(18 /$ $20)+2] \times(13 / 16)\} / 3249 \times 100 \%$.

The adjusted prevalence of LS was 0.64 using the equation $\{23+[17 \times(32 / 37)+6] \times(23 / 26)\} / 6501 \times 100 \%$, the adjusted prevalence of male LS was $0.55 \%$ using the equation $\{9+[8 \times(13 / 15)+3] \times(9 / 10)\} / 3252 \times 100 \%$, and the adjusted prevalence of female LS was $0.67 \%$ using the equation $\{14+[7 \times(19 / 22)+3] \times(14 / 16)\} /$
$3249 \times 100 \%$. No gender predominance was observed in the adjusted prevalence of SS and LS (Table 1).

\section{Socioeconomic and psychological characteristics}

Table 2 shows the socioeconomic and psychometric characteristics of SS $(n=19)$, LS $(n=23)$, and NS $(n=30)$. All three groups comprised middle-aged subjects [SS (38.4 \pm 6.9$)$, LS (38.5 \pm 7.0$)$, and NS $(39.1 \pm 7.5$ years old)] with female predominance (60.9-68.4\%). The three groups shared similar body mass index (21.8-23.7). The majority of subjects in the three groups was married (93.3$100 \%)$ and employed (60.9-78.9\%). Only a few of the subjects in the three groups had frequent intake of coffee, alcohol, or cigarettes, while one-third of the subjects in each group often drank tea. On the other hand, SS earned more money, lived in larger houses, and had higher education levels than LS and NS, but the difference in the family incomes of SS and NS did not reach statistical significance. LS had higher SRQ scores than NS and higher EPQ-neuroticism scores than SS. The sleep durations in the 2-week sleep logs were significantly different among the three groups [SS $(4.7 \pm 0.4 \mathrm{~h})$, LS $(10.2 \pm 1.1 \mathrm{~h})$, and NS $(7.8 \pm 0.8 \mathrm{~h}), \mathrm{F}=9.206, \mathrm{P}<0.001]$.

After controlling for gender and age, we compared those socioeconomic and psychometric characteristics with differences of $\mathrm{P}<0.10$ (education level, house area, family income, SRQ, EPQ-neuroticism, EPQ-extraversion, and ESS) between SS and LS by logistic regression. LS had higher EPQ-neuroticism scores [odds ratio $(\mathrm{OR})=1.224,95 \%$ confidence interval $(\mathrm{Cl})=1.047-1.409]$ and lower education levels $(\mathrm{OR}=0.740,95 \% \mathrm{Cl}=0.631$ 0.849) than SS.

\section{Polysomnographic characteristics}

Table 3 shows the PSG characteristics of the three groups. According to the sequence of LS, NS, and SS, their durations of TRT, TST, and WASO decreased gradually and significantly. As a result, no significantly different sleep efficiency (TST/TRT) was shown among the three groups. SS spent less time in Stage 2 and REM sleep than LS and NS, while SS had a higher percentage of Stage 3 than LS. Additionally, LS had a higher REM density than SS and NS.

During the daytime MSLT, sleep latency was not significantly different among the three groups. The percentage of SS with mean sleep latency $\leq 8 \mathrm{~min}$ $[52.6 \%(10 / 19)]$ was significantly higher than LS $[8.7 \%$ $(2 / 23)]$. The SOREM was demonstrated in two SS $(2 / 19$, $10.5 \%)$ and three NS (3/30,10.0\%), and no statistical difference was shown.

\section{Discussion}

In the current study, the adjusted prevalences of SS and LS were 0.52 and $0.64 \%$, respectively, without gender predominance. To the best of our knowledge, 
Table 2. Socioeconomic and psychometric characteristics of short (SS), long (LS), and normal sleepers (NS).

\begin{tabular}{|c|c|c|c|c|}
\hline & $S S(n=19)$ & NS $(n=30)$ & $\operatorname{LS}(n=23)$ & Statistics \\
\hline \multicolumn{5}{|l|}{ Socioeconomic characteristics } \\
\hline Age (years) & $38.4 \pm 6.9$ & $39.1 \pm 7.5$ & $38.5 \pm 7.0$ & $F=0.027$ \\
\hline BMI & $21.8 \pm 2.3$ & $23.7 \pm 2.2$ & $23.1 \pm 2.8$ & $F=1.073$ \\
\hline Gender (female), N (\%) & $13(68.4)$ & $19(63.3)$ & $14(60.9)$ & $\chi^{2}=0.264$ \\
\hline Marital status (married), N (\%) & $19(100.0)$ & $28(93.3)$ & $22(95.7)$ & $\chi^{2}=0.410$ \\
\hline Education level (college or above), N (\%) & $9(47.4)$ & $6(20.0)$ & $4(17.4)$ & $\chi^{2}=5.894^{\star} @ \$$ \\
\hline Occupation (employed), N (\%) & $15(78.9)$ & $23(76.7)$ & $14(60.9)$ & $\chi^{2}=2.201$ \\
\hline House area $\left(>90 \mathrm{~m}^{2}\right), \mathrm{N}(\%)$ & $12(63.2)$ & $9(30.0)$ & $6(26.1)$ & $\chi^{2}=7.335^{\star @ \$}$ \\
\hline Family income ( $>10,000 \mathrm{RMB} /$ month), N (\%) & $9(47.4)$ & $8(26.7)$ & $4(17.4)$ & $\chi^{2}=4.345^{\star \$}$ \\
\hline Tea (often), N (\%) & $6(31.6)$ & $11(36.7)$ & $9(39.1)$ & $\chi^{2}=0.264$ \\
\hline Coffee (often), N (\%) & $1(5.3)$ & $0(0)$ & $1(4.3)$ & $\chi^{2}=0.011$ \\
\hline Alcohol (often), N (\%) & $0(0)$ & $2(6.7)$ & $2(8.7)$ & $\chi^{2}=1.422$ \\
\hline Cigarettes (often), N (\%) & $1(5.3)$ & $1(3.3)$ & $0(0)$ & $\chi^{2}=1.079$ \\
\hline \multicolumn{5}{|l|}{ Psychometric characteristics } \\
\hline EPQ-psychoticism & $9.3 \pm 1.9$ & $9.9 \pm 2.7$ & $10.6 \pm 2.0$ & $F=0.736$ \\
\hline EPQ-extraversion & $10.5 \pm 3.7$ & $10.7 \pm 3.3$ & $7.6 \pm 2.4$ & $F=1.994$ \\
\hline EPQ-neuroticism & $6.6 \pm 4.5$ & $7.4 \pm 3.9$ & $11.2 \pm 3.4$ & $\mathrm{KW}=4.209^{* \$}$ \\
\hline EPQ-lie & $9.5 \pm 4.1$ & $8.9 \pm 3.2$ & $8.8 \pm 3.5$ & $F=0.178$ \\
\hline TAQ & $21.6 \pm 6.3$ & $20.9 \pm 7.0$ & $23.0 \pm 8.4$ & $F=0.206$ \\
\hline BDI & $2.3 \pm 2.2$ & $2.4 \pm 1.9$ & $2.6 \pm 2.5$ & $K W=0.133$ \\
\hline SRQ & $4.2 \pm 3.3$ & $2.8 \pm 2.4$ & $6.8 \pm 3.7$ & $\mathrm{KW}=5.701^{\star \&}$ \\
\hline STAI & $68.9 \pm 13.7$ & $71.3 \pm 16.2$ & $81.3 \pm 9.1$ & $F=1.684$ \\
\hline STAI-state & $34.1 \pm 8.6$ & $34.5 \pm 8.0$ & $38.0 \pm 5.3$ & $F=0.708$ \\
\hline STAI-trait & $34.8 \pm 6.3$ & $36.8 \pm 8.2$ & $43.3 \pm 4.7$ & $F=1.534$ \\
\hline MEQ & $57.2 \pm 9.6$ & $56.8 \pm 6.5$ & $53.0 \pm 3.4$ & $F=0.613$ \\
\hline ESS & $7.5 \pm 4.0$ & $6.1 \pm 3.7$ & $9.4 \pm 7.4$ & $\mathrm{KW}=3.026$ \\
\hline Mean sleep duration in sleep log $(\mathrm{h})$ & $4.7 \pm 0.4$ & $7.8 \pm 0.8$ & $10.2 \pm 1.1$ & $F=9.206^{* @ \$ \&}$ \\
\hline
\end{tabular}

BMI: body mass index; RMB: Ren Min Bi (Chinese yuan); EPQ: Eysenck Personality Questionnaire; TAQ: Type A Questionnaire; BDI: Beck Depression Inventory; SRQ; Self-Report Questionnaire; STAI: Spielberger State/Trait Anxiety Inventory; MEQ: Morningness/ Eveningness Questionnaire; ESS: Epworth Sleepiness Scale; KW: Kruskal-Wallis test; F: one-way ANOVA. *P<0.05, ${ }^{@}$ NS compared to SS; ${ }^{\$}$ LS compared to SS; ${ }^{\text {LS }}$ compared to NS.

these data have never been reported. Only one previous study of more than one million subjects reported $4.0 \%$ of subjects sleeping $5 \mathrm{~h}$ or less per night and $1.7 \%$ of subjects sleeping at least $10 \mathrm{~h}$ per night. However, not all of the subjects in that study would qualify as SS or LS according to ICSD-2 criteria (14). Compared to previous studies, the prevalence of subjects sleeping $5 \mathrm{~h}$ or less per night in our study was significantly lower (1.9 vs 4.0\%, $\left.\chi^{2}=189.220, P<0.001\right)$, and the prevalence of subjects sleeping at least $10 \mathrm{~h}$ per night in our study was significantly higher $\left(2.1\right.$ vs $1.7 \%, \chi^{2}=116.020$, $\mathrm{P}<0.001)$. These differences might be due to the following reasons. First, the methods of calculating sleep duration were different. The previous study collected sleep duration information with one question "On the average, how many hours do you sleep each night?" and coded the answers in categories from 2 to $9 \mathrm{~h}$. We calculated mean sleep duration by mean TIB minus 0.25 . Furthermore, the subjects in the previous study were much older $($ men $=58 \pm 10$ and women $=57 \pm 11$ years of age) than in our study (men $=39.1 \pm 7.3$ and women $=37.9 \pm 6.6$ years of age). It is well known that sleep duration can steadily decrease with age (27), which might contribute to more SS and fewer LS than in the previous study. Finally, it should be noted that the prevalence of SS and LS in the middle-aged Chinese population was a crude estimate, since the data might be distorted by potential factors such as limited ability to study a small number of SS and LS and an arbitrary judgment of health status of subjects in Phase 1.

In the current study, SS earned more money, attained higher educational levels, and lived in larger houses than LS. Because of steadily increasing demands and the desire to stay awake for a longer time during the day, it is understandable that SS have more opportunities for better social achievements than LS. In addition, the literature suggests that SS and LS have different personalities (28-31), so their specific personalities might play important 
Table 3. Polysomnographic (PSG) characteristics of short (SS), long (LS), and normal sleepers (NS).

\begin{tabular}{|c|c|c|c|c|}
\hline & SS $(n=19)$ & NS $(n=30)$ & $\operatorname{LS}(n=23)$ & Statistics \\
\hline \multicolumn{5}{|l|}{ Nocturnal PSG } \\
\hline \multicolumn{5}{|l|}{ Sleep continuity } \\
\hline TRT (min) & $314.4 \pm 43.2$ & $479.0 \pm 41.1$ & $572.0 \pm 19.9$ & $F=11.077^{\star @ \$ \&}$ \\
\hline TST (min) & $280.1 \pm 45.0$ & $418.6 \pm 42.3$ & $470.8 \pm 53.6$ & $\mathrm{~F}=9.772^{\star @ \$ \&}$ \\
\hline Sleep efficiency (\%) & $89.1 \pm 7.4$ & $87.4 \pm 5.7$ & 82. $3 \pm 10.1$ & $F=2.550$ \\
\hline Sleep latency (min) & $10.3 \pm 5.7$ & $9.7 \pm 6.3$ & $12.3 \pm 7.9$ & $F=1.350$ \\
\hline REM latency (min) & $79.5 \pm 33.9$ & $83.5 \pm 32.8$ & $76.5 \pm 20.6$ & $F=1.706$ \\
\hline REM density & $18.8 \pm 6.4$ & $21.6 \pm 7.4$ & $30.0 \pm 11.1$ & $F=3.922^{\star \$ \&}$ \\
\hline WASO (min) & $34.3 \pm 20.1$ & $60.4 \pm 22.6$ & $101.2 \pm 58.2$ & $\mathrm{~F}=8.741^{\star @ \$ \&}$ \\
\hline Arousals index & $7.4 \pm 4.0$ & $9.0 \pm 3.9$ & $12.5 \pm 3.1$ & $F=2.334$ \\
\hline \multicolumn{5}{|l|}{ Sleep architecture } \\
\hline Stage 1 (min) & $19.3 \pm 6.5$ & $33.5 \pm 7.5$ & $32.0 \pm 8.7$ & $F=3.227$ \\
\hline$\%$ Stage 1 & $6.9 \pm 3.2$ & $8.0 \pm 3.1$ & $6.8 \pm 2.1$ & $F=1.832$ \\
\hline Stage 2 (min) & $168.6 \pm 43.2$ & $249.9 \pm 64.8$ & $289.5 \pm 81.3$ & $\mathrm{~F}=8.406^{\star @ \$}$ \\
\hline$\%$ Stage 2 & $60.2 \pm 7.8$ & $59.7 \pm 9.8$ & $61.5 \pm 25.7$ & $F=0.925$ \\
\hline Stage 3 (min) & $25.7 \pm 10.7$ & $28.0 \pm 12.8$ & $20.3 \pm 7.9$ & $F=1.402$ \\
\hline$\%$ Stage 3 & $9.2 \pm 3.0$ & $6.7 \pm 2.7$ & $4.3 \pm 3.3$ & $F=4.005^{\star \$}$ \\
\hline REM sleep (min) & $66.4 \pm 15.9$ & $107.2 \pm 41.7$ & $129.0 \pm 55.1$ & $\mathrm{~F}=6.013^{\star @ \$}$ \\
\hline$\%$ REM sleep & $23.7 \pm 7.1$ & $25.6 \pm 4.7$ & $27.4 \pm 10.8$ & $F=0.772$ \\
\hline \multicolumn{5}{|l|}{ MSLT } \\
\hline Mean sleep latency & $9.7 \pm 4.5$ & $11.4 \pm 4.1$ & $13.1 \pm 4.0$ & $F=2.183$ \\
\hline Mean sleep latency $\leq 8 \mathrm{~min}, \mathrm{~N}(\%)$ & $10(52.6)$ & $7(23.3)$ & $2(8.7)$ & $\chi^{2}=10.587^{\star \$}$ \\
\hline$\geqslant$ SOREM, N (\%) & $2(10.5)$ & $3(10.0)$ & $0(0)$ & $\chi^{2}=1.895$ \\
\hline
\end{tabular}

TRT: total recording time; TST: total sleep time; REM: rapid eye movement; WASO: wake after sleep onset; MSLT: multiple sleep latency test; SOREM: sleep-onset REM. ${ }^{\star} \mathrm{P}<0.05$, ${ }^{\circledR}$ difference between SS and NS; ${ }^{\$}$ difference between LS and SS; ${ }^{\circledR}$ difference between LS and NS. F: one-way ANOVA.

roles in determining their social achievements at the same time.

In the current study, LS had high levels of neuroticism, and Eysenck (19) judged that clusters of anxiousness, fearfulness, and nervousness characterized higher neuroticism scores (19). A meta-analysis of 148 studies suggested that neuroticism might indicate a susceptibility for other temperamental traits, such as negative emotions, an inability to control urges, a disposition to complain, inefficient ways of coping with stress, a tendency to appraise events as stressful, a tendency to have unrealistic ideas, or a person's habitual level of distress (32). Hicks et al. (9) hypothesized that LS had higher levels of problem-focused coping, which made them less effective in dealing with life's stresses. This is consistent with some temperamental traits of neuroticism. Thus, neuroticism might contribute to higher levels of psychological distress and lower social achievement in the LS in the current study. On the other hand, conclusions about neuroticism in SS and LS in previous studies are contradictory, including findings that LS were more neurotic $(28,33)$, that SS were more neurotic $(8,31,34)$, or that there was no significant difference between SS and LS $(6,35)$. It should be noted that most studies that do not show more neuroticism in LS evaluated neuroticism using an anxiety inventory, not a personality inventory. It is known that the interpretation of anxiety is not unambiguous. For example, Hicks et al. (8) found that SS had higher scores in a particular anxiety, and that a particular anxiety could be interpreted as a measure of drive level, so it would in turn support LS as being more neurotic (28).

In the current study, although their sleep durations were hugely divergent, SS, NS, and LS shared similar durations of Stage 3 sleep. In addition, LS spent more time in REM sleep and Stage 2 sleep than SS. All of these results were consistent with most previous studies $(4,10,12)$. The results may suggest that Stage 3 sleep is essential for humans, because it was stable among subjects with different sleep durations. This is an interesting topic that should be explored through further study. Similar to some previous studies, LS had higher REM densities than SS $(4,10)$. Aserinsky (36) hypothesized that REM density was an index of sleep satiety, because REM density increased with prolonged sleep duration and eventually became saturated at a maximal level. Thus, the higher REM density in LS might be due to a long sleep duration. 
It was interesting that nearly half of SS had a short mean sleep latency ( $\leq 8 \mathrm{~min}$ ) in the MSLT, which was of the same severity as that required for a diagnosis of narcolepsy or idiopathic hypersomnia according to the ICSD-2 (3). Additionally, a previous study in France suggested that SS $(<6 \mathrm{~h})$ among $25-45$-year-old participants were not a homogeneous group, but included both insomniacs and subjects with or without sleep debt (37). However, after a comprehensive clinical interview and a sleep laboratory assessment in the current study, insomnia, sleep debt, and physic/mental/sleep disorders associated with hypersomnia should have been excluded. Furthermore, SS shared similar subjective sleep propensities (ESS) with NS and LS. We assumed that low levels of neuroticism might allow SS to fall into sleep easily. Of course, this assumption should be treated cautiously, and SS with a short mean sleep latency ( $\leq 8 \mathrm{~min}$ ) should be followed over a long term to assess their health status.

Our study has some limitations. The prevalence of SS and LS were much lower than expected, but the final sample size was relatively small, which limited its statistical power. Therefore, these results need to be replicated in future studies with larger sample sizes. Another major limitation was the predominance of women, which might overlap the characteristics of male subjects because more than $60 \%$ of participants were females.

\section{References}

1. Klingenberg L, Sjodin A, Holmback U, Astrup A, Chaput JP. Short sleep duration and its association with energy metabolism. Obes Rev 2012; 13: 565-577, doi: 10.1111/ j.1467-789X.2012.00991.x.

2. Stamatakis KA, Punjabi NM. Long sleep duration: a risk to health or a marker of risk? Sleep Med Rev 2007; 11: 337 339, doi: 10.1016/j.smrv.2007.07.006.

3. AASM. International Classification of Sleep Disorders: Diagnostic and Coding Manual. 2nd edn. Westchester: American Academy of Sleep Medicine; 2005.

4. Hartmann E, Baekeland F, Zwilling G, Hoy P. Sleep need: how much sleep and what kind? Am J Psychiatry 1971; 127 : 1001-1008.

5. Hartmann E. Sleep requirement: long sleepers, short sleepers, variable sleepers, and insomniacs. Psychosomatics 1973; 14: 95-103, doi: 10.1016/S0033-3182 (73)71362-1.

6. Webb WB, Friel J. Sleep stage and personality characteristics of "natural" long and short sleepers. Science 1971; 171: 587-588, doi: 10.1126/science.171.3971.587.

7. Hicks RA, Pellegrini RJ. Locus of control in short and long sleepers. Percept Mot Skills 1978; 47: 1337-1338, doi: 10.2466/pms.1978.47.3f.1337.

8. Hicks RA, Pellegrini RJ, Hawkins J. Test anxiety levels of short and long sleeping college students. Psychol Rep 1979; 44: 712-714, doi: 10.2466/pr0.1979.44.3.712.

9. Hicks RA, Marical CM, Conti PA. Coping with a major stressor: differences between habitual short- and longersleepers. Percept Mot Skills 1991; 72: 631-636, doi: 10.
Finally, the target sample was recruited from parents of primary school-aged children, so the sleep patterns of a couple might affect each other. In the current study, no couple was recruited as an SS, LS, or NS at the same time. Additionally, these parents may not accurately represent the general population.

In this study, the crude estimates of the prevalences of SS and LS were 0.52 and $0.64 \%$, respectively, with no gender differences. LS had lower social achievements and higher levels of neuroticism than SS. In addition to different sleep durations, neuroticism might contribute to differences in social achievements between SS and LS during the same time period. Stage 3 sleep might be essential for humans, since the groups with different sleep durations shared similar Stage 3 sleep times. In addition, the short MSLT results ( $\leq 8 \mathrm{~min}$ ) in $\mathrm{SS}$ should be interpreted with caution.

\section{Acknowledgments}

Research supported by the Guangzhou Municipal Bureau of Education Science and Technology Program (\#08A036), the National Natural Science Foundation of China (\#30800303), and the Guangdong Natural Science Foundation (\#06300309). 2466/pms.1991.72.2.631

10. Webb WB, Agnew HW Jr. Sleep stage characteristics of long and short sleepers. Science 1970; 168: 146-147, doi: 10.1126/science.168.3927.146.

11. Aeschbach D, Cajochen $C$, Landolt $H$, Borbely AA. Homeostatic sleep regulation in habitual short sleepers and long sleepers. Am J Physiol 1996; 270: R41-R53.

12. Aeschbach D, Postolache TT, Sher L, Matthews JR, Jackson MA, Wehr TA. Evidence from the waking electroencephalogram that short sleepers live under higher homeostatic sleep pressure than long sleepers. Neuroscience 2001; 102: 493-502, doi: 10.1016/S03064522(00)00518-2.

13. Aeschbach D, Sher L, Postolache TT, Matthews JR, Jackson MA, Wehr TA. A longer biological night in long sleepers than in short sleepers. J Clin Endocrinol Metab 2003; 88: 26-30, doi: 10.1210/jc.2002-020827.

14. Kripke DF, Garfinkel L, Wingard DL, Klauber MR, Marler MR. Mortality associated with sleep duration and insomnia. Arch Gen Psychiatry 2002; 59: 131-136, doi: 10.1001/ archpsyc.59.2.131.

15. Li SX, Zhang B, Li AM, Wing YK. Prevalence and correlates of frequent nightmares: a community-based 2-phase study. Sleep 2010; 33: 774-780.

16. Zhang J, Li AM, Kong AP, Lai KY, Tang NL, Wing YK. A community-based study of insomnia in Hong Kong Chinese children: Prevalence, risk factors and familial aggregation. Sleep Med 2009; 10: 1040-1046, doi: 10.1016/j.sleep.2009. 01.008 . 
17. First MB, Spitzer R, Williams JBW, Gibbon M, Williams JWB. User's guide for the structured clinical interview for DSM-IV axis I disorders: SCID-II clinician version 1996. New York: American Psychiatric Association; 1996.

18. Johns MW. Reliability and factor analysis of the Epworth Sleepiness Scale. Sleep 1992; 15: 376-381.

19. Eysenck H, Eysenck S. Manual of the Eysenck Personality Questionnaire. London: Hodder and Stoughton; 1975.

20. Shek DT. Reliability and factorial structure of the Chinese version of the Beck Depression Inventory. J Clin Psychol 1990; 46: 35-43, doi: 10.1002/1097-4679(199001)46:1< 35::AID-JCLP2270460106>3.0.CO;2-W.

21. Chen CN, Wong J, Lee N, Chan-Ho MW, Lau JT, Fung M. The Shatin community mental health survey in Hong Kong. II. Major findings. Arch Gen Psychiatry 1993; 50: 125-133, doi: 10.1001/archpsyc.1993.01820140051005.

22. Shek DT. The Chinese version of the State-Trait Anxiety Inventory: its relationship to different measures of psychological well-being. J Clin Psychol 1993; 49: 349-358, doi: 10. 1002/1097-4679(199305)49:3<349::AID-JCLP2270490308 $>3.0 . \mathrm{CO} ; 2-\mathrm{J}$.

23. Zhang $B$, Hao $Y L$, Wing $Y-K$. The reliability and validity of Chinese version Morningness/Eveningness Questionnaire. Chinese J Behav Med Sci 2006; 15: 856-858.

24. Zhang BY. The development and psychometric evaluation of Type A Questionnaire. Acta Psychol Sinica 1983; 15: 434-439.

25. Iber C, Ancoli-Israel S, Cheeson AL Jr, Quan SF for the Academy of Sleep Medicine. The AASM Manual for the Scoring of Sleep and Associated Events: Rules, Terminology and Technical Specifications. 1st edn. Westchester: American Academy of Sleep Medicine; 2007.

26. Carskadon MA, Dement WC, Mitler MM, Roth T, Westbrook PR, Keenan S. Guidelines for the multiple sleep latency test (MSLT): a standard measure of sleepiness. Sleep 1986; 9: 519-524.

27. Ohayon MM, Carskadon MA, Guilleminault C, Vitiello MV. Meta-analysis of quantitative sleep parameters from childhood to old age in healthy individuals: developing normative sleep values across the human lifespan. Sleep 2004; 27 : 1255-1273.

28. Hartmann E, Baekeland F, Zwilling GR. Psychological differences between long and short sleepers. Arch Gen Psychiatry 1972; 26: 463-468, doi: 10.1001/archpsyc.1972. 01750230073014.

29. Hicks RA, Grant F, Chancellor C. Type A-B status, habitual sleep duration, and perceived level of daily life stress of college students. Percept Mot Skills 1986; 63: 793-794, doi: 10.2466/pms.1986.63.2.793.

30. McKelvie SJ. Sleep duration and self-reported Type A behavior: a replication. J Psychol 1992; 126: 285-289, doi: 10.1080/00223980.1992.10543362.

31. Sexton-Radek K. Clinical aspects associated with adjustment in unusual sleepers. Percept Mot Skills 1998; 87: 261262, doi: 10.2466/pms.1998.87.1.261.

32. DeNeve KM, Cooper H. The happy personality: a metaanalysis of 137 personality traits and subjective well-being. Psychol Bull 1998; 124: 197-229, doi: 10.1037/0033-2909. 124.2.197.

33. Skinner NF. Neuroticism, extraversion and sex differences in short and long sleepers. Psychol Rep 1983; 53: 669-670, doi: 10.2466/pro.1983.53.2.669.

34. Gau SF. Neuroticism and sleep-related problems in adolescence. Sleep 2000; 23: 495-502.

35. Fichten CS, Libman E, Creti L, Bailes S, Sabourin S. Long sleepers sleep more and short sleepers sleep less: a comparison of older adults who sleep well. Behav Sleep Med 2004; 2: 2-23, doi: 10.1207/s15402010bsm0201_2.

36. Aserinsky E. The maximal capacity for sleep: rapid eye movement density as an index of sleep satiety. Biol Psychiatry 1969; 1: 147-159.

37. Leger D, Roscoat E, Bayon V, Guignard R, Paquereau J, Beck F. Short sleep in young adults: Insomnia or sleep debt? Prevalence and clinical description of short sleep in a representative sample of 1004 young adults from France. Sleep Med 2011; 12: 454-462, doi: 10.1016/j.sleep.2010.12. 012. 